\title{
Disordered Eating Patterns in University Students and Links with Stress Coping; a Literature Review and Discussion
}

Power JJ*

Queen's University Belfast, Nursing, 97 Lisburn Road, Belfast, BT97BL, UK

\begin{abstract}
Aim: To provide a narrative review of the literature and discussion addressing the issue of young university undergraduate students, patterns of disordered eating and the relationship between stress and stress coping.

Background: The term disordered eating reflects the spectrum of disturbed eating patterns, including anorexia nervosa and bulimic nervosa. In the last three decades a significant amount of research has been undertaken internationally in relation to this area, with increasing concern as disordered eating impacts upon the individual's long-term health prospects, but also their ability to function and achieve as undergraduate students.
\end{abstract}

Methods: A narrative review and discussion of the literature from 1980, against 7 databases with assessment of the papers applying a quality criteria scale. 35 papers were finally included for consideration in this review.

Conclusion: There are a large number of young undergraduate students probably struggling with or at risk from disordered eating. A significant proportion of this may be undisclosed and presents sub-clinically. There may be issues relating to mental health in some of the cases, but the literature suggests at least a proportion of the students are perhaps struggling with stress/distress and poorly developed coping resources. The emergence of or exacerbation of disordered eating may present as a negative coping response.

The discussion and review suggests a need for greater qualitative enquiry to expose more of the student's voice in terms of eating and their stress/distress experience. Such deeper enquiry might better inform support for young students in managing stress in the early years at University.

Keywords: University students; Disordered eating; Stress; Coping

\section{Introduction and background}

This literature review seeks to explore, evaluate and discuss the literature relating to disordered eating within university undergraduate students and possible links with stress and coping mechanisms. The prevalence of disordered eating may be relatively high within populations of students, particularly and including first year students.

Disordered eating represent an over focus on body shape and weight reflecting in conditions marked by abnormal and disrupted attitudes to food and patterns of eating, that might involve periods of both excessive intake of food or significantly insufficient intake of food and may involve the use of medications or emetics to maintain body weight [1-5]. Disordered eating can form part of a spectrum of disturbed eating patterns and behaviour presenting both in terms of significant and evident disability (clinical anorexia nervosa, bulimia nervosa and binge eating) or as a 'subclinical syndrome' but with a significant risk of psychological, social and physiological damage [6-11]. Whilst perhaps seen as more predominant Western phenomena, increasing evidence suggests emergent patterns in developing countries, including India [12-13], although by way of some contrast [14] report from a large Chinese study significantly lower levels of at risk students.

Symptoms of disordered eating are distressing to individuals and are apparently not uncommon amongst the university population, although perhaps often concealed or presenting sub-clinically. There is significant actual and potential morbidity attaching to disordered eating and evidence suggests low engagement with the support services for those experiencing or at risk from disordered eating [15]. The possible reasons for this are the stigma attaching to disordered eating $[16,17]$ suggest that perhaps $90 \%$ of disordered eating occurs in individuals up to 25 years of age. Studies from a number of countries have suggested an interesting variation in the range of disordered eating. de Hart et al. [18] conclude from their study that possibly $13.5 \%$ of female college students and $3.6 \%$ of the male college students reflected eating disorder symptoms. Although preceding their time at university, there is perhaps significant relevance to [19] very large Chinese study with junior and high school student (pre-university) $(\mathrm{n}=5473)$ suggesting significant correlation between life stress and students eating behaviours.

The first year as a university student may present particular challenges and expose particular vulnerability in the younger student population, representing a new and challenging environment, with sometimes quite different ways of learning requiring adaptation to an academic model and with often far greater focus upon self-discipline, directed self-learning and the prioritisation of work [20]. The first year as an undergraduate university student can be significantly stressful [21-25]. Individuals cope with stress in various ways [26-28]. Disordered eating may represent a coping mechanism in periods of acute/on chronic stress [29-33]. We know that stress may contribute to or trigger patterns of disordered eating $[34,35]$. These students may then be showing signs of disordered eating which could, in some cases,

*Corresponding author: Dr John J Power, Lecturer (Education), Queen's University Belfast, Nursing, 97 Lisburn Road, Belfast, BT97BL, UK, Tel: 02890972392; E-mail: j.power@qub.ac.uk

Received November 23, 2016; Accepted March 03, 2016; Published March 10 2016

Citation: Power JJ (2016) Disordered Eating Patterns in University Students and Links with Stress Coping; a Literature Review and Discussion. Adv Practice Nurs 2:108. doi: 10.4172/2573-0347.1000108

Copyright: $\odot 2016$ Power JJ, et al., This is an open-access article distributed under the terms of the Creative Commons Attribution License, which permits unrestricted use, distribution, and reproduction in any medium, provided the original author and source are credited. 
be understood as a negative coping mechanism in addressing stressors [36,37], including perhaps the transition to higher education.

\section{Searching Strategy (Methods)}

The approach adopted by the researcher was to map key concepts that underpin the focus of the literature review, the main types of supporting evidence and to identify areas of importance and interest where there was limited informative research [38-41].

Based within and reflecting the approaches suggested by researchers [42-44] the literature review worked to a specific inclusion and exclusion criteria and published research literature is the main evidential source. The review does not constitute a formal systematic review of all the material available in the field, but as suggested in the research texts (ibid) it was undertaken to provide a broader enquiry into the state of knowledge of the field, to incorporate and reflect on existing literature reviews within the subject field, and to explore the gaps in existing research knowledge and understanding [45-50]. Particularly the approach adopted was a narrative review of the literature [51], possibly better lending itself to a wider range in scope, reflection and discussion of the literature, and less restrictive in terms of inclusion and exclusion criteria [52]. In preparing the literature review the researcher addressed the following key steps: the identification of a focus for a literature review, the identification of studies relevant to the research question, the selection of studies to include in the review, the charting of information within the included studies, collating and summarising the results of the studies. The search explored seven 7 databases. Medline 1980-Cinahl, Web of Science, Psycinfo, Pubmed, Scopus, QCat Classic, QCat is the reviewers own University article search engine.

The inclusion/exclusion criteria for data bases addressed whether the study was well-structured relative to the research question; was the literature current; did the sample represent the study population; were the field methods piloted; was there evidence that ethical considerations addressed; was there a clearly focused conclusion supported by the study and was the study approach and conclusions comparable with related studies. Specifically this comprised;

Databases were searched from 1980 earlier studies might not inform current experience and practice that the papers were relevant, credible, with significant evidence of contributory value to the review That research papers and text were accessible in English. That research papers and text or original text or copies were accessible through the researcher's university institution or available through interlibrary loans. This criteria reflected practical accessibility.

\section{The exploration and comparison of international findings}

The use of key terms and phrases was developed from reading the background literature and relative studies, discussion with research colleagues and discussion with students. Initially the term 'university students and disordered eating/ eating disorders' was searched. This was refined with the addition of 'stress coping. The terms 'university students' 'stress coping' and 'eating disorders/disordered eating' were also searched. In total this produced some 274 results. The abstracts were reviewed looking particularly for younger undergraduate university students, stress coping and disturbed eating patterns (eating disorder or disordered eating). Finally some 35 papers were selected and considered to be both relevant to the study and particularly helped to inform the research question and objectives of the study.

\section{The charting of information and data within the included studies}

Although the research papers and review articles were not formally weighed, each was assessed against a three-point scale for quality criteria. Each of the papers was then collated for year of study; country of origin; aim of the study; study population; relevance of methodology and research methods; outline of study findings and where appropriate demography of study population.

\section{Results}

The results of the literature review are outlined and discussed in the following headings (1) prevalence of disordered eating (2) patterns of disordered eating (3) risk factors (4) university students stress, coping, and disordered eating.

\section{Prevalence}

In a study with US university undergraduate and postgraduate students noted high incidence of disordered eating pathology with evidence of relatively low treatment seeking [53]. This was one of the few studies reviewed that employed randomised methods and published the questionnaire response rate relative to the target population, at least to the initial part of the study, although there was a much smaller sample evident within the second part (follow-through) of the study. The authors suggested that possible reasons for low treatment seeking might include the impact of stigma. The authors also concluded that possibly between $9 \%-13 \%$ of female students manifested significant sub-clinical disordered eating; this possibly correlates with an earlier study undertaken by [54] suggested that possibly $11.9 \%$ of female university students demonstrated behaviours which might be seen as 'sub risk' for bulimia nervosa, in that study [55]. In a large mixed gender Turkish university student study suggested young females' were significantly at greater risk. The authors also suggested $22.8 \%$ of the students were found to have eating disorders, with a significant proportion representing sub-clinically 'mild form of eating disorder, i.e. an eating problem'. However, in a more recent study from a Thai university the authors suggested that the prevalence of disordered eating behaviour was only evident in about $4.7 \%$ of the female undergraduate student population; this co-related with body image dissatisfaction, social pressures and academics stress [56-58] suggested within the literature review for their study that a potentially significant proportion of individuals experiencing disordered eating at 'sub threshold levels' rather than those presenting with classical symptoms and more reflective of a continuum of disturbed patterns of eating.

Sulkowski et al. [59] Reported from a large Chinese study within Anhui province only $5.3 \%$ of females and $4 \%$ of male university students acknowledged disordered eating attitudes; a fairly large subject sample $(n=1328)$ of 16-24-year-olds. The authors noted that higher levels of parental education appeared to correlate with increased indication of disordered eating attitudes. The questionnaire reliability was pre-tested in a pilot study and the internal consistency of the questionnaire was positively measured employing Cronbach's alpha for scale reliability. However, the study while seeking to explore attitudes used a selfadministered questionnaire to a convenience sample of students.

Again in a recently published French study involving up to $10 \%$ of the student population in Upper Normandy ( $\mathrm{n}=3457)$, [60] suggested high prevalence of eating disorders amongst university students (20.5\%). Although very relevant, this study is also limited by 
the use of convenience sampling and the attempts to assess complex social and emotional drivers for patterns of disordered eating, through quantitative enquiry.

\section{Patterns of disordered eating}

In their UK based longitudinal study of university students suggested that the presence of disordered eating often precedes the student's arrival at university and that patterns of eating remained relatively stable whilst the students were at university [61]. The study explored significant numbers of students $(n=343$; mean age $=17.6)$ with a follow through retrospective self-report questionnaire. The studies validity was limited by the use of a convenience sample and little detail of the nature of the questions that were addressed. Again the proportional response to the questionnaire relative to the study population was not indicated. As before the study was perhaps also limited by the use of a single quantitative methodology to explore complex sensitive and contextual issues. Taylor et al. [62] suggested no significant change in eating patterns during the period of their 'longitudinal study' with US female university students; although the study seems to have been longitudinal, the time line was only two months. In addition and of interest the authors suggest that perhaps some $40 \%$ of the female college students' manifest disordered eating patterns. However, in an earlier US university study [63] noted worsening patterns of disordered eating particularly evident amongst female students by the end of the their first year and associated with perceptions of weight, level of attractiveness significant levels of perceived stress and reduced levels of self-efficacy [64] suggested that the new and stressful university environment could have some impact upon patterns of eating behaviour, a view apparently supported by Treasure [65] when considering 'at risk' students $(n=142)$ in a study with undergraduate students explored the concept of an eating disorder continuum and subclinical variations of disordered eating' [66]. They suggest that the new environment of college, separation from family, making new friends in an unfamiliar and challenging environment can have particular impact in the development of disordered eating. Notwithstanding the authors noted that most students do not develop patterns of disordered eating and the study sought to explore protective factors. Importantly they suggest that health care professionals and student counsellors should be aware of the continuum of disordered eating i.e. seen as a spectrum. They concluded that assisting students with their personal-emotional adjustment to college (e.g. by empowering them to feel more in control of environmental stressors) could help them to maintain healthy eating attitudes and behaviours.

\section{Risk Factors}

In a study undertaken with Canadian undergraduate university students employed a questionnaire to both female students and to their mothers [67]. Disordered eating was associated with perceptions of reduced reciprocity with parents a sense of incompetence (on the students' part), with a pattern of avoidance and lack of identity commitment, noted as a significant psychological indicator of at risk female students. The study also suggests significant correlation between 'rigidity' in the approach to parenting, eating disorder pathology, sense of incompetence and reduced sense of self-determination /control. Ward and Hay [68] suggest that the consequences of negative comments (within the family) can impact negatively on body image and selfesteem; with disordered eating reflecting in some cases experiences of emotional abuse and neglect. Other risk factors include peer environments that involve social comparison and teasing, experiences of social transition such as international migration, exposure to negative media messages and genetic vulnerability [69-71]. Again these studies might suggest the importance of both a more predictable and stable perception of the world (comprehensibility) and a more supportive matrix in which to function (manageability).

In a US university undergraduate student study suggested that gender was the primary predictor reflected in disordered eating [72]. The next most significant predictor was the individual's level of self-esteem. In addition other key impacting factors were a drive for perfectionism and whether individuals used escape coping when subject to significantly perceived stressors. Other studies suggest behaviour manifests within dietary restriction; overeating or binge eating with the presence of compensatory behaviour sometimes involving purging; with evidence of low self-esteem; externalized locus of control; limited self-efficacy and pattern of depression.

In a recent paper reporting to a US study involving three universities and a significant number of mixed gender students $(\mathrm{n}=$ 2604) suggested that a number of undergraduate students 'engage in a variety of disturbed eating behaviours'. This appears to correlate with levels of anxiety and depression and obsessive compulsive activity, with a disproportionate number of younger women reflecting lower levels of self-esteem. The authors particularly reflect on how this coalesces with the 'developmental stage of emerging adulthood' and the importance of the 'socio-cultural environment as a source of potentially powerful influence on 'eating behaviours and body image'.

As noted by other researchers suggest that apart from obvious issues with weight, body image and a significant pre-occupation with food, disordered eating can reflect or correlate with low self-esteem, limited self-efficacy and patterns of depression. The issue of stress, low self-esteem and disordered eating was addressed by in an Italian high school study. Evidently some of the participants were over 18 years of age although it was not clear from the paper the mean age range of the female students. The study was of some significance as eight schools were involved with a range of students $(n=171)$ and the authors concluded that stress may precipitate disordered eating where there were predisposing psychological factors, particularly pre-existing low self-esteem.

\section{University Students Stress and Coping}

In another UK based study with undergraduates $(n=675)$, in applying Rotter's model $(1966 ; 1990)$ concluded that higher levels of self-esteem and an internalized locus of control significantly reflected in students ability to cope with the early demands of university life also concluded that female university students appeared to be more at risk from the effects of stress/distress and coping and that generally students should be exposed to more effective models of stress management.

In a US study involving female university students $(n=28)$ concluded that part of the issue for the study group in terms of their mal-adaption to stress was in their perception/ exaggerated perception of stress and a preoccupation with body image and food.

Suggested the importance of appraisal and perception of the potential stressor. In a study involving Tasmanian university students the authors underlined the importance and value of developing cognitive hardness in relation to both stress appraisal and management. Cognitive hardness is reflected in a sense of control or influence upon events, a sense of value attaching to oneself and the perception of change as challenge rather than threat.

In a fairly large mixed gender UK study involving both undergraduate and Open University students $(n=409)$ explored 
health in relation to a sense of coherence (SOC) addressing the three stress management principles/ conditions of comprehensibility, manageability and meaningfulness. The authors concluded that a reasonably developed SOC reflected a more internalised locus of control, that the individual valued their worth, with more evidence of internal stability and a positive 'trustfulness' in life. The authors suggested that an enhanced SOC also contributed to the management of stress. An external locus of control is significantly associated with anxiety, a sense of helplessness and frustration, contrasting with the empowered and self-efficacious qualities attaching to an internal locus of control, with a lower experience of stress; there appears to be some difference in interpretation of the same or similar situations dependent upon an internal or external locus.

In a fairly large study involving first-year undergraduate students at a mid-sized university in Canada underlined how the transition to first-year university life can present both a significant opportunity for development but also can be a substantial source of stressors to the new undergraduate student both in terms of the academic demands, adjusting to university life and trying to establish themselves within a new and often challenging social milieu. The early first year of university life can impact negatively on the undergraduate's self-esteem (ibid). The authors suggested that social support can be significantly protective for undergraduate student in reducing the impact of stressors and in facilitating more positive adjustment. They concluded (inter-alia) that increased social support particularly from friends (but interestingly not from family) could be predictors of enhanced adjustment to university life and reflected positively at a personal and at an academic level; with evidence of enhanced self-esteem amongst the undergraduates explored college students' stress and the influence of interpersonal relationships on a Sense of Coherence. The authors suggested that coming to university was a high stress experience for many of the new students in another study involving US undergraduate students suggested the value of 'protective factors in both managing and preventing stress', in a study undertaken with a group of Greek female university students, suggested that emotional intelligence reflecting self-awareness and significant interpersonal relationships appeared to help support the students and function as buffers against disordered eating. This would seem to reflect the conclusion of earlier review paper concluding a reasonable correlation between stress, coping styles and patterns of disordered eating.

In a US study involving young adults attending university reported that disordered eating was more associated with reduced mental health and the use of 'emotional eating. Both gender and also the early patterns of 'comfort eating' were also significant cues to emotional eating behaviour in young adults. The study underlines the need for training and support to children and young adults in the use of more positive coping mechanisms and the need for better training to caregivers and those supervising young university students, in a South African study involving female first-year students explored the background of increased stress and the risk of negative coping for female students who were potentially predisposed to developing disordered eating, as a consequence of the transition from high school to university. There appeared to be a significant correlation between perceived stress and increased risk of disordered eating. Again the authors concluded that perceived stress appeared to directly correlate with disordered eating again in an American university undergraduate study $(n=409)$ suggested that a number of the students used avoidance coping including engaging in disordered eating as a distracter from stressors. Limited self-efficacy appeared also to correlate positively with increased disordered eating. The authors concluded that students who perhaps already use avoidance coping and have a poor concept of self-efficacy are more at risk from disordered eating as stressors built. The authors suggested the need for a developmental programme of stress coping with new undergraduates, running through from orientation to the university large French mixed gender study of university students suggested that eating disorders were significantly prevalent and associate with (inter alia) stress and limited coping techniques. A study that seemed to provide a significant breadth of understanding, but again a more triangulated or crystallised approach to methodology and methods could have elicited more depth of understanding. The limitations of the existing research evidence suggested some significant correlation between disordered eating, body dissatisfaction and stress coping. This study looked particularly at first year US female college students and concluded that more effective coping strategies can mitigate the damaging relationship between stress and eating patterns. This study was also limited by a convenience sample, relatively low response rate to an online questionnaire and again an attempt to explore complex areas of human emotion, applying quantitative methods in data collection.

The studies reviewed employed single quantitative methodology. Quantitative methodologies and research methods are measured against principles of validity and reliability. The internal validity of a study can be impacted by (for example) the efficacy of the study design, its' possible impact to bias results, and the external validity of a study could be impacted (again for example) by the selection of subjects and the generalisability of results to the greater theoretical population (ibid.). The reliability of the study reflects the degree to which the research methods consistently measure or reflect the phenomena under investigation; again this might reflect in the level of testing or piloting or seeking informed opinion upon fieldwork methods and field work instruments before embarking upon the full study (ibid.).The efficacy of a quantitative study is probably most significant at experimental level; a less efficacious method is represented by semi/quasi experimental methods and the least internally valid quantitative method would be represented by a non-experimental study. A probability sample is probably more representative of a study population; the more representative the sample to the theoretical population generally, the more externally valid the study is perceived to be (ibid.).Convenience sampling could be considered as the weakest of all sampling methods with significant risk of sampling bias and least reflective of the theoretical population; in addition the sample size (or response rate) relative to the theoretical population, relative to the target population and reflected in the sample group could significantly impact on the external validity/ generalisability of the study (ibid). suggests the sample response rate in excess of $50 \%$ would be considered satisfactory in questionnaire responses; a questionnaire response of less than $30 \%$ could significantly impact on the validity of the study. A technique to assess the efficacy of the sample size relative to the target population might employ 'power calculation/analysis', and this could enhance the validity of the study. As noted and almost exclusively, the research studies examined employed single quantitative methodology. One possible exception is incorporating some open ended questions; however this approach could perhaps have been improved and better triangulated by engaging a selection of the students in interview. Predominantly these studies used self-report questionnaires. The use of self-report questionnaires can both provide a breadth and possibly, dependent upon the sophistication of the questionnaire, some understanding of depth, and limit the interviewer effect on those taking part in the study. A number of the studies originated in US universities and in some cases were discipline specific; this might impact on their generalisability to UK and Europe. In only three of the studies reviewed a convenience sample 
was not used. Nine of the studies provided some detail or outline of the questions used within the study, to better assess the internal validity of the work. In eight of the published studies reports there was no indication of piloting or seeking qualified review and opinion upon the questionnaire, prior to commencing fieldwork. In the absence of a pilot study, the efficacy and validity of the questionnaire could be in doubt. Again in twenty five of the studies it was not entirely clear how the sample population relative to the target population and the theoretical population, were effectively correlated to enhance external validity and the generalisability of the study. Only four of the studies published a percentage calculation of the questionnaire response rate relative to the target population. Only one of the studies noted the use of power analysis in computing the sample, relative to the study population. These factors could all impact negatively upon the external validity reliability and generalizability of the studies. Studies employing single quantitative methodology, concerns about the representative nature of some of the study samples relative to the study population and adequacy of the sample size in some of the studies, could limit the external validity and generalisability of the studies, suggesting some degree of study limitations. Notwithstanding the limitations noted to these papers, the reviewer researcher considered that these studies reflected important outcomes and research potentially valuable to the subject area.

\section{Discussion and Conclusions}

This review of the literature suggests that disordered eating could possibly be significantly prevalent or a significant risk for first year university students and possibly associated with stress suggest high incidence of eating pathology and subclinical disordered eating with evidence of relatively low treatment seeking; possible associated with the stigma of a mental illness. Disordered eating may represent a form of psychopathology, but alternatively and in some cases is possibly more reflective of problems in living. Substantially, the young university undergraduate suffering with or at risk from disordered eating may not be experiencing a sufficient degree of coping and coherence in life.

A sense of effective control is integral to how individuals interpret or respond to stress or stressors, with poor control reflecting more in negative coping responses suggest that women with disturbed eating patterns are noticeably different in the experience (perception) of stress. Particularly important is the individual's appraisal of events and stress coping mechanism.

Reflecting earlier conclusions by suggest the powerful impact of the first year at university upon the undergraduate's self-esteem and ability to effectively adjust to university life both academically and socially. suggest that high levels of stress and stressors in university students can reflect in a range of behavioural pathology, including disordered eating patterns, suggest that individuals with inadequate tolerance to stress (poor coping) may well be functioning at chronic levels of' 'overstress' including disrupted eating patterns. The arrival at university as a first year undergraduate can present significant stressors to the young student, possibly impacting more negatively and damagingly where the students sense of coherence is limited. Stressors can impact on selfesteem and possibly stimulate disordered eating behaviours, or possibly exacerbate pre-existing or dormant conditions.

Coping Skills as an Undergraduate: Coping both depends on the unique characteristics of the individual but also reflects into the structure of support, the matrix in which the individual functions, and an interaction between the stressor, the environment and the individual's perception / response. suggest that stressors are not necessary concrete realities, but are perceptions of reality; social constructs that can therefore be reconstructed. The individual's personal assets qualities and strengths (coping skills) interact positively or negatively with factors reflecting the situation suggest that for undergraduate students who enter college with a predominantly 'avoidance coping style', limited self-efficacy and limited coping skills; when avoidance coping fails to impact on a stressor individuals may resort to patterns of disordered eating to distract from the difficulty, or to exert a form of control when faced with a situation that appears irreconcilable in exploring the impact of stress on the undergraduate students emphasises the importance of a sense of coherence and supportive environment in sustaining the stress coping mechanisms of the student.

Some of the literature emphasises that arrival at university can present significant stressors particularly for under-graduate students' with a limited or underdeveloped sense of coherence. The distress associated with the failure to perceive a stressor as manageable can present as negative coping mechanisms. Again some of the literature suggests that disordered eating (at least for some undergraduate students) represents a negative approach to the management of stress/ distress. The literature also suggests that an enhanced sense of coherence could enable and facilitate these young undergraduate students to a more positive and manageable perception of life and particular situations and application of more positive coping mechanisms when addressing the new arrival at university and the establishment of themselves academically and socially to the challenges facing them within the first year. This could provide significant opportunity for universities to facilitate the development of more positive coping skills with undergraduate students in the early stage at university.

However, what is perhaps significantly lacking from the literature is the student voice, the need for clearer qualitative insight to explore the student's perspective of stress and coping, and what for those students at risk from disordered eating, might better help them and support them in more positive approaches to stress / distress coping.

\section{References}

1. Abouserie R (1994) Sources and Levels of Stress in Relation to Locus of Control and Self Esteem in University Students, Educational Psychology 14: 323-330.

2. Antonovsky A (1987) Unravelling the mystery of health: how people manage stress and stay well. San Fransisco: Josey-Bass p: 218.

3. Antonovsky A (1996) The salutogenic model as a theory to guide health promotion. Health Promotion International 11: 11-18.

4. Ball K, Lee C (2000) Relationships between psychological stress, coping and disordered eating: A review. Psychol Health 14: 1007-1035.

5. Beasley M, Thompson T, Davidson J (2003) Resilience in response to life stress: effects of coping style and cognitive hardiness, Personality and Individual Differences 34: 77-95.

6. Beat (2013) Beating Eating Disorders.

7. Beaukes M, Walker S, Esterhuyse K (2010) The role of coping responses in the relationship between perceived stress and disordered eating in a cross-cultural sample of female university students. Stress and Health 26: 289-291.

8. Berg KC, Frazier P, Sherr $L$ (2009) Change in eating disorder attitudes and behavior in college women: prevalence and predictors. Eat Behav 10: 137-142.

9. Ruggiero GM, Bertelli S, Boccalari L, Centorame F, Ditucci A, et al. (2008) The influence of stress on the relationship between cognitive variables and measures of eating disorders (in healthy female university students): a quasiexperimental study. Eating and Weight Disorders 13: 142-148.

10. Bergh Z (2006) Personality: Individual differences in work performance. In Bergh Z, Theron A (eds.), Psychology in the work context .Cape town: Oxford University Press. 
Citation: Power JJ (2016) Disordered Eating Patterns in University Students and Links with Stress Coping; a Literature Review and Discussion. Adv Practice Nurs 2:108. doi: 10.4172/2573-0347.1000108

Page 6 of 2

11. Boyd C (2006) "Coping and Emotional Intelligence in Women with a History of Eating Disordered Behaviour," McNair Scholars Journal 10: 4-12.

12. Brown SJ (2014). Evidence-based nursing-the research practice connection (3rd edn.), Burlington: Jones and Bartlett learning.

13. Stephen LB, Schiraldi, Glenn R, Wrobleski P (2009) and Association of Eating Behaviours and Obesity with Psychosocial and Familial Influences. American Journal of Health Education 40: 80-89.

14. Chemers MM, Hu Li-tze, Garcia BF (2001) Academic self-efficacy and first year college student performance and adjustment. Journal of Educational Psychology 93: 55-64.

15. Cilliers F, Kossuth S (2002) The relationship between organisational climate and salutogenic functioning. South African Journal of Industrial Psychology 28: 8-13.

16. Costarelli V, Demerzi M, Stamou D (2009) Disordered eating attitudes in relation to body image and emotional intelligence in young women. J Hum Nutr Diet 22: 239-245

17. Darling CA, McWey LM, Howard SN, Spencer OB (2007) College student stress: the influence of interpersonal relationships on sense of coherence, Stress and Health 23: 215-229.

18. DeHart T, Tennen H, Armeli S, Todd M, Mohr C (2009) A diary study of implicit self esteem, interpersonal interactions and alcohol consumption in college students. Journal of Experimental Social Psychology 45: 720-730.

19. Dennard EE, Richards CS (2013) Depression and coping in subthreshold eating disorders. Eat Behav 14: 325-329.

20. Dissing AS, Bak NH, Pedersen LE, Petersson BH (2011) Female medica students are estimated to have a higher risk for developing eating disorders than male medical students Danish Medical Bulletin 58: A4207.

21. Eisenberg D, Nicklett EJ, Roeder KM, Kirz NE (2011) Eating Disorde Symptoms among College Students: Prevalence, Persistence, Correlates, and Treatment-seeking. Journal of American College Health 59: 700-707.

22. El Ansari W, Clausen SV, Mabhala A, Stock C (2010) How Do I Look? Body Image Perceptions among University Students from England and Denmark International Journal of Environmental Researchand Public Health 7: 583-595.

23. Fennig S, Hadas A, Itzhaky L, Roe D, Apter A, et al. (2008) Self-criticism is a key predictor of eating disorder dimensions among inpatient adolescent females International Journal of Eating Disorders 41: 762-765.

24. French SA, Leffert N, Story M, Neumark-Sztainer D, Hannan P, et al. (2001) Adolescent binge/purge and weight loss behaviors: associations with developmental assets. J Adolesc Health 28: 211-221.

25. Friedlander LJ, Reid GJ, Shupak N, Cribbie R (2007) Social support, selfesteem, and stress as predictors of adjustment to university among first year undergraduates, Journal of College Student Development 48: 259-274.

26. Frydenberg E (1997) Adolescent Coping: Theoretical and research perspectives. London; Routledge.

27. Gan WY, Mohd Nasir MT, Zalihah MS, Hazizi AS (2012) Psychological distress as a mediator in the relationships between biopsychosocial factors and disordered eating among Malaysian University students. Appetite 59: 679-687.

28. Gerrish K, Lacey A (2010) The Research Process in Nursing. Oxford: Willey Blackwell.

29. Gillham B (2000) Developing a questionnaire (real world research). London: Continuum.

30. Gross R, Kinnison N (2007) Psychology for Nurses and allied health professionals, London: Hodder Arnold.

31. Harvey L, Drew S (2006) The first year experience: a review of the literature for the Higher Education Acedemy.

32. Hobfoll SE (1989) Conservation of resources. A new attempt at conceptualizing stress. Am Psychol 44: 513-524.

33. Hou F, Xu S, Zhao Y, Lu Q, Zhang S, et al. (2013) Effects of emotional symptoms and life stress on eating behaviors among adolescents. Appetite 68: 63-68.

34. Johnson M (2004) Approaching the salutogenesis of sense of coherence: the role of 'active' self-esteem and coping. Br J Health Psychol 9: 419-432.
35. Jordan J (2002) Let the survey take the strain. The Safety \& Health Practitioner 20: $25-29$

36. Lazarus RS, Folkman S (1984) Stress, appraisal, and coping. New York Springer.

37. Macneil L, Esposito-Smythers C, Mehlenbeck R, Weismoore J (2012) The effects of avoidance coping and coping self-efficacy on eating disorder attitudes and behaviors: a stress-diathesis model. Eat Behav 13: 293-296.

38. Maltby J, Williams G, McGarry J, Day L (2012) Research Methods for Nursing and Health Care. Harlow: Pearson Education Limited.

39. Moksnes UK, Espnes GA, Lillefjell M (2012) Sense of coherence and emotional health in adolescents. J Adolesc 35: 433-441.

40. Morrison V, Bennett P (2009) An Introduction to Health Psychology (2nd edn.) Harlow: PearsonEducation

41. (2013) National Institute of Clinical Excellence (NICE) National Collaborating Centre for Mental Health.

42. Pattanathaburt P, Somrongthong R, Thianthai C (2013) Prevalence of disordered eating behaviours, body image dissatisfaction, and associated factors among Thai female undergraduate students. International Journal of Health Promotion and Education. 51: 151-160.

43. Perieira RF, Alvarenga M (2007) Disordered Eating: Identifying, Treating, Preventing and Differentiating it from Eating Disorders, Diabetes Spectrum 5 : $141-148$.

44. Pokrajac-Bulian A, Zivcic-Becirevic I (2005) Locus of Control and Self-Esteem Has Correlates of Body Dissatisfaction in Croatian University Students. European Eating Disorders Review 13: 54-60.

45. Polit DF, Beck CT (2010) Essentials of Nursing Research (7th edn.) Philadelphia: Lippincott Williams \& Wilkins.

46. Quick VM, Byrd-Bredbenner C (2013) Disturbed eating behaviours and associated psychographic characteristics of college students. Journal of Human Nutrition and Dietetics 26: 53-63.

47. Rotter JB (1966) Generalized expectancies for internal versus external contro of reinforcement. Psychol Monogr 80: 1-28.

48. Rotter JB (1990) Internal versus external control of reinforcements: A case history of a variable. American Psychologist 45: 489-493.

49. Royal College of Psychiatrists (2011) Mental Health and Students in Higher Education.

50. Sampson A (2009) Stress and College/University Students, Berlin: Lambert Academic Publications.

51. Sanlier N, Yabanci N, Alyakut O (2008) An evaluation of eating disorders among a group of Turkish university students. Appetite 51: 641-645.

52. Sassaroli S, Ruggiero GM (2005) The role of stress in the association between low self-esteem, perfectionism, and worry, and eating disorders. Int $\mathrm{J}$ Eat Disord 37: 135-141.

53. Sharan P, Sundar AS (2015) Eating Disorders in Women. Indian Journal of Psychiatry 57: 286-295

54. Shea M, Pritchard ME (2007) Is self-esteem the primary predictor of disordered eating? Personality and Individual Differences 42: 1527-1537.

55. Simon-Boyd G, Bieschke JK (2003) predicting eating disorder continuum groups: hardness and college adjustment, Poster Presentation Annual Conference of the American Psychological Association.

56. Streubert HJ, Carpenter DR (2007) Qualitative Research in Nursing. Advancing the Humanistic perspective. (4th edtn) New York: Lippincott Williams \& Wilkins.

57. Steinhardt M, Dolbier C (2008) Evaluation of a resilience intervention to enhance coping strategies and protective factors and decrease symptomatology. J Am Coll Health 56: 445-453.

58. Striegel-Moore R, Silberstein IR, French P, Rodin J (1989) A prospective study of disordered eating among college students. International Journal Of Eating Disorders 8: 499-509.

59. Sulkowski ML, Dempsey J, Dempsey AG (2011) Effects of stress and coping on binge eating in female college students. Eat Behav 12: 188-191.

60. Szasz T (1960) The Myth of Mental Illness. American Psychologist 15: 113-118. 
Citation: Power JJ (2016) Disordered Eating Patterns in University Students and Links with Stress Coping; a Literature Review and Discussion. Adv Practice Nurs 2:108. doi: 10.4172/2573-0347.1000108

Page 7 of 2

61. Tavolacci MP, Grigioni S, Richard L, Meyrignac G, Déchelotte P, et al. (2015) Eating Disorders and Associated Health Risks Among University Students Journal Nutrition Education and Behaviour 47: 412-420.

62. Taylor CB, Bryson S, Doyle AAC, Luce KH, Cunning D, et al. (2006) The adverse effect of negative comments about weight and shape from family and siblings on women at high risk for eating disorders. Pediatrics 118: 731-738.

63. Taylor JS (2004) Salutogenesis as a framework for child protection: literature review. J Adv Nurs 45: 633-643.

64. Thøgersen-Ntoumani C, Ntoumanis N, Cumming J, Chatzisarantis NL (2011) When feeling attractive matters too much to women: A process underpinning the relation between psychological need satisfaction and unhealthy weight control behaviours, Motivation and Emotion 35: 413-422.

65. Treasure JA (2009) A Guide to the Medical Risk Assessment for Eating Disorders. Kings College London. South London and Maudsley NHS Trust.

66. Vohs KD, Bardone AM, Joiner TE, Abramson LY, Heatherton TF (1999) Perfectionism, perceived weight status, and self-esteem interact to predict bulimic symptoms: A model of bulimic symptom development. Journal of Abnormal Psychology 4: 695-700.

67. Walker J, Payne S, Smith P, Jarrett N. (2012) Psychology for Nurses and the Caring Professions (4th edn.) Maidenhead: OU Pres.

68. Ward RM, Hay MC (2015) Depression, coping, hassles, and body dissatisfaction: factors associated with disordered eating. Eat Behav 17: 14-18.

69. Wheeler HA, Wintre MG, Poliy J (2003) Association of Low Parent-Adolescent Reciprocity, a Sense of Incompetence, and Identity Confusion with Disordered Eating .Journal of Adolescent Research 18: 405-429.

70. Wingfield N, Kelly N, Serdar K, Shivy VA, Mazzeo SE (2011) College students' perceptions of individuals with anorexia and bulimia nervosa. Int J Eat Disord 44: 369-375.

71. Wonderlich-Tierney AL, Vander Wal JS (2010) The effects of social support and coping on the relationship between social anxiety and eating disorders. Eat Behav 11: 85-91.

72. Yu J, Lu M, Tian L, Lu W, Meng F, et al. (2015) prevalence of disordered eating attitudes among university students in Wuhu, China. Nutr Hosp 32: 1752-1757. 